\title{
Changes in the Relation of Education System, School and Youth in the Horizon of Ambivalencies of Modernisation.
}

\author{
Werner Helsper \\ (Martin-Luther-Universitat Halle) \\ Merle Hummrich \\ (Martin-Luther-Universität Halle)
}

The changes that have taken place in Germany's education system in recent years must be understood in the horizon of comprehensive processes of social transformation. This transformation can be seen from a global, a European, and a specifically German perspective. The German perspective is to be distinguished firstly in terms of comprehensive changes, secondly with reference to the shifts between the federal level and that of federal states (,Kulturhoheit der Länder"), and thirdly, for the transformation processes of the German reunification since 1990 .

Here a first step will determine central lines of social transformation, clarifying their significance for the changes in the education system. Secondly, changes in the conditions of growing up for children and adolescents will be exemplarily illustrated vis-à-vis the school. Finally, central research developments will be sketched, and the connection between the processes of social transformation and the conditions of matuing will be summarized in thesis.

\section{The Transformation of the Education System in the Horizon of the Ambivalencies of Modernisation}

If processes of social transformation are understood as processes of modernisation, then the danger exists always of evaluating societies along an axis of more or less modernized. Diagnoses are hastily voiced-as in the case of the German-German unification-like partially modernized, catching up or selective modernisation (Helsper i. a. 2001), which present more or less deficitary constructions. In order to escape these hasty judgements, transformation processes 
are regarded here from the perspective of ambivalences or antinomies (e. $\mathrm{g}$. Giddens 1995).

\subsection{Antinomies of Modernisation}

What do we understand as ambivalencies or antinomies of modernisation? We presume that the occurence of processes of modernisation is not linear, but always give rise to counterprocesses: Thus processes of individualisation, for example, are not ambivalent in themselves, but are also accompanied by new dependencies and compulsions. Modernisations are therefore not understood as lines of ascension to a better state, but as internally tense processes which also generate contrary processes. We distinguish between four such antinomies of modernisation (cf. Helsper i. a. 2001):

- The antinomy of individualization,

- The antinomy of rationalization,

- The antinomy of pluralization or differentiation, and

- The antinomy of civilization.

The ambivalence of individualization describes the tense situation of the release of the individual from traditionally determined forms and patterns of living. Thus, individuals'freedom of choice grows on the one hand.. and the identity of individuals becomes more open, fleeting, disparate and changeable. The individuum is in a world of ideologically differentiated partial systems, in none completely at home, a “wanderer between worlds”. „Patchwork identities” and „DIY-biographies” are generated in which individua assemble miscellaneous material to self-collages. This also means, however, that the individua are now more responsible for the arrangement of their lives. They are now confronted with a "compulsion to freedom." To deal with different plans for the future in reflection, to form one's résumé in the horizon of a multiplicity of options, also presents new burdens. Additionally, this new freedom often coincides with a dissolution out of one's "Lebenswelten" and a slackening of social connections. This reduces the immediate social and alien control through locally bound communities, which opens up new leeway for development. With this, though, coincides also what Anthony Giddens (1995, pp. 33ff.) calls „exbedding”. It can 
therefore, aside from the opportunities for freedom, also lead to a ,burden of freedom." The new dependencies, which develop in order to this process are rooted less in the immediate normative control. Control and dependency are passed on rather to abstract, systematic and organisational compulsions. The individuals are now delivered over unto these, all new freedom notwithstanding.

This marks the starting point of the antinomy of rationalization, which means: Firstly, abstract system imperatives and regulatory media which individuals cannot influence start to intrude ever more into the formation of life contexts, and put them under rationalisation pressure. Variations on the stock market, appreciation and depreciation of currencies, etc. can deeply transform, or even break down living circumstances and regional milieus. Secondly, the position of control through social society on a smaller scale-without such control mechanisms having to fall away entirely-the independence of social organisations. These stand for the assurance of universalist participation, rights and securities on the one hand. Simultaneously, though, they also introduce norms and regulations that abstract from the peculiarities of the individuals. In recent years, a development has even taken place in which the individuals on the one hand become ever more dependent upon organisations and their regulations. On the other hand, though, the organisations point out to the individuals their own autonomy and self-responsibility. So the seemingly paradoxical situation arises that organisations that also act as a securing force for individuals now demand of them ever more a self-responsible self-reliance. The abstract compulsions and dependencies take on ever more the form of a compulsion to self-reliance and self-responsible individuality.

Thereby generalisations are addressed which are accompanied by counterprocesses of multiplication and diversification, of small scale differences and local differences. This tension can be called pluralisation ambivalence. It finds its most distinct expression in the widespread globalisation in the area of culture. Brands, signs, styles and meanings are spread over the entire world, easily to be called up and accessed everywhere in the world. Thereby national, regional and local traditions and schemes of meaning come under generalisation pressure: they are irritated and permeated by globally fed generalised patterns of meaning 
and lifestyles. Simultaneously therewithal in different locales and cultural contexts alternative world interpretations also become accessible.. With this the horizons of meaning are augmented and stocks of cultural interpretation are decentred. They become plural and more varied. From out of the mixing together of local and regional interpretaion stocks new schemes of meaning and cultural patterns can be created and assembled. This generates a new complexity, which appears on the one hand as enablement of variety-as post modern schemes bring out; on the other hand this process is accompanied by the end of the great narrations. So a sign of a modernised, reflexive modernity is a radical plurality and heterogeneity generated in part through generalization of cultural interpretation stocks, of schemes of meaning, of interpretations of the world and of oneself, as well as of life situations and lifestyles themselves. Not least of all, the really occuring wanderings and migrations of recent decades have added the experience of ethnic and cultural difference to this interplay of cultural generalisation and pluralisation.

In the course of these lines of modernisation the freed individual passes into a new relation to himself. He stands before himself, becomes self-reflective, learns to observe himself-an attitude which also becomes necessary, if the individual is to ensure his orientation and self-responsible organisation of his own life in the complex, highly modernised society. In connection with the systemic compulsions and the economies of action and time resulting from the processes of rationalisation, the individual must also oversee and discipline himself ever more strictly. The individual must in a sense take up the rationalisation in his own self -if he wants to last through the processes of social rationalisation. The individuals being required to stand before themselves, observing and controlling his activities, the discovery and social construction of the subjective world is brought about. Therein an inner, subjective universe of passions, yearnings, feelingx and demands opens up. This is cultivated in aesthetic fields of experience, conceived in aesthetic forms and released as a new level of demands for subjective happiness, love, nearness and experientiality. This simultaneity of increased demands for self-discipline and on the other hand for the expanding 
demands for emotional recognition and love as exactly this unique human, as well as exstatic sensual experiences can be conceived as civilisation antinomy.

How can the central changes in Germany's system of education in recent decades be located with relation to these ambivalencies of modernisation? In what follows some of the most significant changes in the education systemwithout any claim to completeness-are taken up.

\subsection{The German Education System in the Horizon of the Antinomy of Individualisation}

The German school system exhibits a strong external grouping (Hauptschule, Realschule, Gymnasium, sometimes Gesamtschule) in difference to other European school systems (e. g. Finnland or Sweden). At 10 pupils are divided into the different school forms quite early. In empirical research on educational inequality it is often confirmed that this early division of children into a lower, a middle and a higher level of education contributes considerably to the development of this educational inequality in Germany. This inequality seems to reproduce itself again and again, as the PISA studies (Baumert i. a. 2001, Prenzel i. a. 2004) show. These results can then be read as an expression of a reproductive orientation of the German school system that apparently knows little mobility and individualisation, but only apparently! For within these reproductive structures, grave changes to greater individualisation have taken place:

- In spite of the continuingly strong inequality of educational opportunities, a strong expansion of diplomas in the realm of higher education has occured-an almost fivefold increase of highschool diplomas since the 1950's unto nearly a third of the class in West Germany. And within three years after the turn in East Germany from c. $11 \%$ at the end of the 1980 's to over $30 \%$ in the "new“ Bundesländern in the 1990's (cf. Helsper/Hummrich 2005). In the course of this expansion of higher education, the middle school diploma after the tenth class has become the new standard diploma. In this course adolescents from formerly uneducated and migrant milieus now have new options for continuing educated careers.

- As well, the distinct increase in educational aspirations since the 1950's: 
Parents more and more refuse Hauptschule, the lowest level, diploma for their children, but want their children to attain the Abitur, with the coinciding license to study at a university. Thus, a distinct increase in educational aspirations occured, all the way to those castes and milieus that were once far removed from education.

- Finally, there is a significant tendency toward the detachment of diploma and school form, as well as a differentiation of continuing education careers in different school types. Thus, many education titles can already be attained at career schools and school diplomas can be attained at other school forms then the regular schools. Hence the paths to educational diplomas have become opener and more various. As well, multiple regional and local differentiations at the level of the federal state lend to the German school system a high degree of differentiation and of complexity.

All this can be understood as biographicising and individualisation of courses of scholastic education, albeit a slowed individualisation, reproductively formed over in the context of strong and early external differentiation of school forms. In this context the ambivalency of individualisation sketched is also realised in the educational sector: via the sketched detachment, diversification and biographicising of courses of education the chances for the individual to participate in continuing education grow. Thus subjective transformations, milieu changes, changes of life situation and lifestyle become increasingly possible. With all expansion of educational options, though, a new „,education requirement“ can be spoken of: one who does not at least attain the middle diploma qua the new standard is already ,,internally excluded“ from the education system (cf. Bourdieu i. a. 1997). And in the course of the expansion of education options, this is ever more often interpreted as individual failure - as self-responsible exclusion from other life opportunities. Educational freedom is thus mixed with educational compulsion, an educational burden and the threat of exclusion. This contributes to a paradoxon of education: Increased educational efforts are called for, biographical education plans and self-supervised education work, i. e. stronger investment in education. At the same time, though, there is no certainty that these efforts can also be traded in for future life opportunities. 


\subsection{Further Tendencies in the German Educational System under the Perspective of Modernising Ambivalencies}

Some further developments in the German education system shall here be mentioned briefly: Dealing with school as organisation presents one further central line of school development. In Germany there was up until the most recent past-again in distinct contrast to other countries, in which e. g. quasieducational markets were generated (e. g. the Netherlands, England, etc.) -a strong state control of the school system at the level of organisational norms. Although this state control still remains, the last decade has seen increased efforts toward a strengthening of schools' autonomy, e. g. in the form of school program development. By this paedagogical action's own logic as well as the teachers' and scholastic agents' room for action on location are strengthened according to the concrete circumstances and starting positions. The abstract, formal organisational prestructures are loosened and rendered more flexible, although they never really could regulate concrete action, as more recent organisational theory shows. This does not mean, however, that in the school system there are no longer any effective control imperatives. Rather the control of is redistributed from the strong regulation of inputs and entry requirements to the control of output with the help of standards and national assessments. Thus, on the one hand, the formal, bureaucratic and administrative regulations are loosened. At the same time, though, the new dynamics of rationalisation and ambivalence can be noticed here: to a far greater extent than before, binding, normative standards are now set down for all schools, all teachers and all pupils, and controlled comprehensively. For the accomplishment of these, in the sense of a "world curriculum", now even globally oriented standards, though, which order and outline new criteria for rationality, the individual pupils, the teachers on location are now made responsible and instructed of their responsibility for the formation of the school.

Even the German school system is marked by a stronger heterogeneity in the form of growing differences between the schools. This is especially true of elementary school (up to the fourth class), which still takes all children of a 
certain age. Distinct differences can, however, be seen in the heterogeneity of the pupils according to the social constitution of the neighbourhood. The German school system produces on the one hand through its early separation of pupils in the fifth class quite homogenous school and class populations. Nevertheless, these homogenised classes are quite heterogenous. Especially in Gesamtschulen and Hauptschulen, pupils of the most various ethnic origins, and "drop outs" from the preparatory schools as well are collected. Thus Hauptschulen are quite homogenous regarding the social background of pupils' families insofar as the pupils collected here come from families with very little economic and cultural capital. From an ethnic and intercultural perspective, though, these classes are -especially in the inner city-extremely heterogenous. To this heterogeneity is then added the differentiation of youth cultural styles which encounter one another in schools. All in all, it must be noted that the German school system has been hitherto marked by a dominance of homogenising, has developed little competence in the treatment of heterogeneity, and therefor the reflexive treatment of the ambivalency of pluralisation in the system of education is not especially well formed.

The German school system has-according to the public paedagogical functionalising under national socialism and in the GDR-rather grown into a "teaching school" in the course of the past few decades, in spite of all differences between individual school profiles. Circumspect paedagogical intentions, the orientation toward the whole formation of a young "character" and the spreading out over young people's entire lives have taken the back seat. This is apparent also in comparison to Japan, whose school system is much more strongly oriented toward a circumspect rearing of its pupils (cf. Toyama-Bialke 2002, Busse/Helsper 2004). This stronger "abstinence" vis-à-vis circumspect paedagogical intentions is on the one hand an understandable attitude before the background of two German dictatorships (national socialism and GDR socialism). On the other hand experiences of distance and of non-jurisdiction over children, adolescents and their families on the part of schools. Demands for a stronger sense of a school's responsibility for the pupils qua persons, a stronger personal, affectively near, supportive attitude vis-à-vis pupils, a greater respon- 
sibility for their lives and affairs-demands that were already voiced in the reform era of the 1960's and 1970's in the old Federal Republic-are currently being discussed again from two perspectives: firstly before the background of the strong social disadvantagement in the German school system already sketched. In this context the school is accused of doing too little to foster and support migrant children and children from less educated milieus, and of being too passive in paedagogical compensation. Secondly, the necessity of a stronger rearing supervision of the pupils on the part of the schools is deduced from the structural transformation of the family (single-parent families, two income families, growth of new poverty and marginalisation of children, etc.). Both lines are intertwined in the present discussion of the "whole day school," which is to become more of a scholastic "Lebenswelt" for the pupils, in which they can better be fostered and supported. While in other countries-as also in Japan-a discussion is in progress on whether the strong responsibility of the school for the lives and affairs of adolescents ought not be relaxed, in Germany a discussion of whether the school ought not take on more jurisdiction over the pupils is presently being held. This development can also be connected to the ambivalence of civilisation alread sketched. The demands for emotional support and resonance contribute to the stronger demands on the school and its professional agents due to the destabilisation of juvenile life contexts. However, not only for the sake of ,emotional recognition,“ but above all, because juveniles from socially marginalised and emotionally destabilised life contexts are especially unable to muster that individualised form of selfcontrol and selfdiscipline that is necessary for educational success and quality.

Also the transformation of the East German school system-just as in the case of the many other East European education systems after the dissolution of the Warsaw Pact-can be understood as placements into the ambivalencies of modernisation: Whereas the East German school system was rather homogenised and uniform, it has now become more differentiated and plural. Where once ,paternalistic,“ authoritarian patterns dominated, it has become individualised and more strongly determined by far-reaching compulsions of placement. Where it once was on the one hand marked by near, strong rearing 
attitudes, an expansion onto the pupil's entire person, it is now more limited, specific and distanced trollformen, (cf. Helsper i. a. 2001,). The consequences of these transformation processes, the restructuring at the level of institutions has by now been well investigated in its significance for teachers, pupils and schools.

\section{The Significance of the School for Children and Adolescents}

The changes in the education system are without a doubt quite significant for the processes of socialisation and education of children and adolescents. School, and formal educational institutions, though, only constitute a field of action. The processes and antinomies of modernisation affect not only the education system and the relation of pupils to school, but in general the conditions of growing up (Krüger/Grunert 2002, Helsper/Böhme 2004). From thence, the conditions of growing up are, for children and adolescents, marked by the development in, and especially the interaction of the different areas of action-school, family, youth support, peers, media and youth culture. And these lead to important structural changes for the phase of youth in particular:

- One result is the lengthening of adolescence-independent from milieu, life situation, and lifestyle. Those growing up become ever sooner "adolescents." Demands of co-and self-responsibility, of youth cultural participation, of friendship creep into ever earlier ages, changing the relation of the generations to one another. Simultaneously, the transition into maturity is delayed by longer courses of education and training ever further for ever more adolescents.

- This coincides with the transformation of adolescence-formerly a brief transition for most maturing persons to early adulthood-into a phase of life in its own right, with its own claims. To try oneself out, to experiment with plans and styles for oneself, to remain open for different experiences becomes the trademark of highly modernised youth. This stands very well in stark contrast to the demands already sketched, that one must regulate and organise one's own educational career with great self-discipline and goal orientation.

- This temporal expansion and pluralisation of adolescence as a phase of life with its own demands is closely connected to the expansion of medial youth 
culture, youth cultural worlds of experience and expressive spaces, as well as the global expansion of medial youth culture and the pluralisation of regional juvenile sub- and counterculture. Juvenile cultural forms of knowledge and practices, boundaries and demands for orientation vis-⿳亠㐅⿵-vis the differentiated symbolic world of juvenile styles and scenes.

- This expanded time of youth all its own, and the expansion and differentiation of youth cultural spaces contributes to the increased participation of adolescents in informal, juvenile cultural educational opportunities, aside from the formal processes of learning and education. The knowledge acquired there, the cultural skills and practices developed there relativise the formal, official scholastic educational options, in a way competing with them. Thus adolescents can acquire the creative competencies so stimulating for them, most especially in informal youth cultural educational contexts. Together with the expansion of new medial, virtual worlds of knowledge and informational opportunities, a relativising of formal, institutional knowledge accesses-a further relativising of the contentual significance of "school's monopoly on knowledge and mediation," also results. This also contributes to a relativisation and a new adjustment of the relation between adults, parents, teachers and other representatives of adult culture, and the more strongly independent juveniles.

It must be stressed that these structural changes only receive their specific form in concrete life contexts in the interaction of social status, milieu, region gender and ethnos. These structural changes thus affect all adolescents in extensively modernised societies, but each in a specific and proper form. This leads to an overall diversification and great heterogeneity of juvenile life situations and life forms. In what follows, we shall focus on specific aspects of this whole context of extensively modernised youth.

Processes of social transformation are always also relevant for the system of education and the agents who participate in it. While in the first chapter of this contribution it was demonstrated to what extent the education system itself is affected by change, and how central fields of scholastic agents' action transform (keyword: familial change, relationship to extrascholastic peer-contexts), we 
shall now be dealing with the phase of adolescence, which presents a grave process of change for young people, as it is with this phase that decisive processes of the development of autonomy are bound. In order to be able to work out the current circumstances of the maturing of German adolescents in interplay with different socialising fields of action, we shall here focus on the school and place this area in relation with other rearing areas of life. In so doing, we shall inquire first into the significance of various life situations and milieus for scholastic integration. Secondly, we shall delve into the relations of adolescents to family, school and others of the same age. The final topic will be the individual preconditions of adolescents with regard to the question of educational success.

\subsection{On the Significance of Various Life Situations and Milieus}

The PISA study was already mentioned above with regard to its significance for the change in the system of education. The comparative studies completed in the years 2000 and 2004 revealed especially the dependency of educational success from the social situation. Thus, the social differences resulting from educational expansion were not cancelled. A weakening of social differences can be asserted at the most in the case of the middle school diplomas. The Gymnasium diploma still presents a great barrier for kids from blue collar families. This inequality is on the one hand due to the relations of the adolescents to milieu and life situation: The less educated the parents household is, the more unlikely is their children's educational success. On the other hand, the inequality also in part due to the impermeability of the education system: when pupils are already at a Hauptschule, they have only a small chance of changing to a preparatory school. Children from blue collar families must at the same time show better achievements than children from the upper social position, in order to receive the same school recommendation after elementary school and are still the ones who most often drop in the educational system.. Belonging to the working class appears, then, to be a problem for the integration into the educational system, which makes clear the relevance of the family and its social position with regard to one's chances for an education. One yet more extreme 
result can be seen in the case of migrant adolescents, who are disproportionately strongly represented in Hauptschulen and Sonderschulen And considerably more migrant adolescents than non-migrants must repeat classes. So, even if the rate of those migrants, who achieve an Abitur has clearly increased since the 1980's, the statistical improbability of educational success in the case of migration indicates a massive efficacy of mechanisms of social inequality. The distance of the parents from education the mechanisms of institutional discrimination, i. e. unequal treatment of equal achievements, and the "language barrier" can be seen as the main reasons for the less than desirable integration into the education system (cf. Hummrich 2002). Concerning the question of gender equality we can say that the girls have currently passed the boys in the school forms for greater achievers, whereas the boys are over-represented in the Hauptschulen and among the dropouts. This means a rapid incline in the educational activity of adolescent females since the 1960's.. But even if the girls have catched up with the boys, girls and young women are strongly disadvantaged in the education system especially after school (cf. Helsper/Hummrich 2005).

Three especially disadvantaged groups can finally be identified: migrant adolescents from families distanced from education, and in which little or no German is spoken, male adolescents from un-or secondarily trained blue collar environments without familial educational aspirations and scholastic support, as well as children and adolescents from multiproblem families, i. e. with a large psychosocial burden and high chance of poverty (Helsper/Hummrich 2005). The educational reform of the 1960's was unable to contribute to an elimination of inequalities, but rather led, at most, to a rise in the level of education. The importing of migrant workers and the migration of their families that followed after in the 1970's led to the formation of new lower classes, which was then also reflected in the education system. The reproduction of social inequalities by the education system must finally also be interpreted as the reproduction of social power and authority relations. Due to this reproductional orientation of the system of education, individual transformation is rendered especially difficult when adolescents are affected by a plurality of social problems. 


\subsection{Relations in School, Family and Peer Groups}

When one considers the development of educational equality, not only systemic circumstances must be regarded. Fields of action and the relations generated therein are also of great significance for the question of success and failure in the education system. As has already been demonstrated, there were, because of the division of Germany, two different education systems up until 1990, upon which different conceptions of rearing and education came to bear. These affected the teacher-pupil-relations. The systemic conditions did not, however, affect the teacher-pupil relation directly. This is apparent from enquiries into scholastic culture (i. e. Helsper i. a. 2001), which also had the processes of transformation after the turn in view. In each scholastic culture, a school forms its own paedagogical ideas and myths, and asserts its own symbolic order (Helsper i. a. 2001). This indicates that school is not only a formalised, bureaucratic and standardised context in which achievement is the exclusive criterium for inclusion or exclusion. Teacher-pupil relations are thus not only marked by specific, role-formed shares, but also by diffuse, proximity-generating shares, differently impressed, each according to the teachers' attitude and school culture. School can, then, be understood as the field of possibility for the formation of teacher-pupil relations, in which recognition, participation and self-responsibility are granted or withheld in specific ways. Adolescents stand finally in specific fitting relationships to their schools and school culture, and are in a certain way interwoven with the institution on the basis of their biographical experiences (Kramer 2002). These biographical experiences are then i. a. influenced by familial relations, which have been characterised by the tendency toward modernisation and informalising since the 1960's. Studies concerned with parent -child relations, and thus also with the relations between generations indicate the wide spectrum of various types of familial relations, ranging from the traditional "do as I say"-household to the various, more or less modernised forms of the negotiation household.. The type of form of relationhip is then also significant for enabling one to have a part in the education system. The parental educational aspiration also plays an important role in the realisation of educational success just as does the social status of the parents and their proximity to, 
or distance from education (Busse/Helsper 2004). This indicates that the cultural capital occupies a special position of value: the presence of cultural goods relevant to everyday life (e. g. a supply of books) and mutual cultural activities (conversation, theatre or concert attendances)-all this affects the course of the school career positively. Strongly restrictive and control-centered paedagogical attitudes taken as a basis for the homework policy tend to coincide with poor achievements in school; a stimulating attitude and the tendency to share common cultural praxes, with positive achievements. Economical capital plays an especially important role in the Gymnasium, beginning with the financing of tutors, and including the possibility to take part in school-complementing learning experiences (foreign language trips and the like).

Finally, the peer group presents a third context of action, to which adolescents can relate inter-and extramurally. Peer contexts, into which adolescents are more bound as they grow older, are generally regarded as supportive and relevant to socialisation. In scholastic contexts adolescent orientations can be found which are school-friendly or-opposed, whereby cliques are often homogenous with respect to their achievements. Simultaneously, school form specific peer-climates can be distinguished: at Hauptschulen the climate is generally school-estranged, at Realschulen school-conformed. At Gymnasien it is more important to conform to performance demands while demonstrating at the same time a distanced attitude toward school, whereas in the Gesamtschule a high appreciation of achievement coincides with a positive attitude toward the school. Peer orientation affects the course of education adversely especially when pupils do not perform because achievements may conflict with peer culture (e. g. the danger of appearing to be a "nerd"). Scholastic success fits generally with family orientation and conformity, resp. integration into the institution, whereas integration into extra-scholastic, juvenile-centered subcultures is to be found especially where conformity is refused, and a characteristically masculine action typus predominates Aside from the expressive subcultural contexts, there is also the integration in clubs, extra-curricular educational institutions and churches, which, again, are dependent upon the milieu in question. This means that the way one spends one's free time in milieus with educational aspirations 
often furthers the acquisition of cultural capital.

The interaction of family, school and peer groups is finally to a great degree significant for the question of educational success. Each person's contacts to the peer group confirm education courses and can serve as compensation, should the need arise. Social inequalities reproduce themselves via the extra-curricular opportunities, rather than being razed. As regards the context of family and school, it must further be concluded that here there are also certain interface constellations that support or hinder educational success. Even if a positive stance toward school and education on the part of the parents can generally be regarded as helpful, just this attitude has its risks, for example when the parent -child relationship becomes dominated exclusively by scholastic concerns, the supportive attitude lacking altogether, or when individual transformation and the development of autonomy are hindered because family and school are homologously structured.

\subsection{Individual Prerequisites for Scholastic Integration}

A conditio sine qua non for learning at all is a structural disposition to the acquisition of knowledge which is can generally be called "child-like curiosity", and thus ascribed to the human dynamics of desire for autonomy, the acquisition of competencies and for validity as a motivational force in children, but which is on the other hand, dependent upon personal dispositions, such as interests and competencies. Scholastic evaluation processes are coped with by adolescents in various ways, though research results from paedagogical psychology indicate that kids' sense of self-worth with respect to their capabilities is made all the more dependent upon scholastic achievements, the further scholastic integration progresses (Helmke 1998). High expectations, restrictive supervision by teachers, competition among pupils; these can lead to achievement anxiety on the part of pupils, especially those who achieve rather poor results. To conclude from this, though, that good pupils per se suffer from less anxiety, whereas poor pupils fear, would be too short: especially the best groups of pupils can show signs of achievement anxiety, because they fear for their position, whereas 
especially at the end of regular school (in the ninth year) the level of anxiety sinks in weaker pupils, because they reduce the relevance of scholastic achievements for their own feeling of self-esteem (e. g. relating more to extra-curricular peer contexts). Indeed, adolescents are less disturbed in their feelings of selfesteem by scholastic achievements, the older they grow.

The social processes of modernisation affect the significance of school ambivalently: on the one hand, diplomas and certificates of education mean ever more; on the other, scholastic success leads to ever fewer guarantees of secure employment. The threat of social isolation in the case of scholastic failure stands therefore over and against a stronger reference to one's own world or peer contextss-a reference which is especially strengthened with age, and through whcih the subjective relevance of school can be reduced. One must not, however, imagine that these contrasting ways of coping were the only ones in the fundamental ambivalence of one's position vis-à-vis school. Ways of acting and relating are also documented that attest to the attempt to treat the suspense experienced in life in such a way that school, on the one hand, presents as little a burden as possible, but such that the threat of isolation seems at the same time less threatening, because beside the significant relation to school, there are also other significant relations.

\section{Perspectives: Growing up in Ambivalencies of Modernisation- Consequences and Prospects for Future Research}

If in conclusion the changes in society, the education system and youth are to be balanced, the task is not simple. The changes described are to complex, interdependent and various. If a "general thesis" is possible, then it may be: growing up under growing modernisation ambivalencies. Here only a few central assertions are to be attached to the explications already made: the antinomies of modernistation present-as the thesis claims - moments of suspense at the level of social and cultural transformations, effective globally for further modernised societies. In specific national and cultural contexts, though, these ambivalencies take on each their own form of expression. Thus they intrude into institutional developments, as was seen from the example of the German school 
system. And in the course of these institutional transformations, the institutions themselves contribute to each specific formation of these modernisation ambivalencies. For pupils it way shown that in the context of the system of education contradictory demands and experiences coincide: e. g. the growing individualisation of courses of education with expanding opportunities on the one hand, accompanied by continuing risks of exclusion along with growing responsibility for one's own educational career, and new dependencies from educational success on the other. Children and adolescents, however, are not only confronted with suspensful developments in one partial system or area of action. Rather, the other fields of learning aside from school are also marked by such ambivalencies. Additionally, the individual areas of action themselvesenter into a strong relation of conflict. This becomes especially distinct in the relation between adolescent culture centered on expressive experientiality and of the school centered on achievement. This results in a multiplicity of various demands to balance out these conflicts, to produce more or less precarious balances and to cope with these challenges. This occurs ever more in local and regional contexts, in which milieu-and group-specific, as well as individual adolescent lifestyles emerge. These are an expression of the heterogenous ways of coming to terms with these demands, which result each from specific local constellations of milieu, gender and ethnos, and which find their expression in pluralised adolescent biographies. In these the specific, individual life stories of the struggle with these ambivalencies can be understood and grasped even unto its very significance for one's own self.

Which consequences follow then, if this thesis can be presupposed, for social and paedagogical research? In what follows, a few lines are sketched, without any claim to completion, which in recent years have been begun, and which must be followed through:

- There must be a greater enquiry into the international and intercultural differences with a comparison of the specific courses and developments of each. This is a path already blazed for the enquiry of differences in selection and educational inequalities, with distinct clues to existing international educational inequalities, but also significant national differences in the educa- 
tion system (cf. Baumert i. a. 2001, Prenzel i. a. 2004).

- There must be more enquiries that relate many levels to one another: here it is important to enquire into multi-level changes in their consequences for socialisation institutions, for contexts of "Lebenswelt," milieus and interaction networks. Many such enquiries into the consequences of institutional changes in the aftermath of the German reunification have been undertaken (cf. Helsper i. a. 2001).

- Studies are of especial importance which examine the interdependencies of the fields of action of youngsters, e. g. the relation of family and school, of family and peers or of school and peers. Such studies (cf. Busse/Helsper 2004) can focus on the complex interaction of varying areas of life, and the demands the hold for adolescents.

- The attachment of macro- and microstudies, of quantitative and qualitative lines of access makes possible a differentiated view of the connestions between structural changes on the macrolevel and the concrete, plural consequences resulting from them for young, maturing people.

- Finally, there must be more studiesthat focus on youngsters' developmental courses, and optimally, connect these with the study of institutions or milieus. Here long term studies have appeared increasingly throughout recent years that focus on the educational processes of young people (cf. e. g. Fend 2000). One further line of research consists of biographical studies on pupils in which the significance of the school and educational processes are located in the entire context of individual lives (cf. Kramer 2002).

The main idea of these notes is that the ambivalencies of growing up are only to be taken in their complexity into the focus of these research approaches: Both in the conflict of global modernisation processes from the macroperspective, and the plural and heterogenous forms of adolescent and youth cultural coping methods of these ambivalencies and the formation of biographic courses contained therein.

\section{Literatur}

Baumert, Jürgen i a. 2001: PISA 2000. Basiskompetenzen von Schülerinnen und 
Schülerinnen im internationalen Vergleich. Opladen.

Bourdieu, Pierre i a. 1997: Das Elend der Welt. Hamburg.

Busse, Susann/Helsper, Werner 2004: Familie und Schule. In: Helsper, Werner./

Bö, Jeanette (ed.): Handbuch der Schulforschung. Opladen: 439-465.

Fend, Helmut. 2000: Entwicklungspsychologie des Jugendalters Opladen.

Giddens, Anthony. 1995: Konsequenzen der Moderne. Frankfurt a. M.

Helmke, Andreas. 1998: Vom Optimisten zum Realisten? Zur Entwicklung des Fähigkeitsselbstkonzeptes vom Kindergarten bis zur 6. Klassenstufe. In Weinert, Franz E. (ed.): Entwicklung im Kindesalter. Weinheim: 115-133.

Helsper, Werner/Böhme, Jeanette/Kramer, Rolf-Torsten/Lingkost, Angelika. 2001: Schulkultur und Schulmythos. Rekonstruktionen zur Schulkultur I. Opladen.

Helsper, Werner/Böhme, Jeanette (ed.). 2004: Handbuch der Schulforschung. Wiesbaden.

Helsper, Werner/Hummrich, Merle. 2005: Erfolg und Scheitern in der Schulkarriere: Ausmaß, Erklärungen, biografische Auswirkungen und Reformvorschläge. In: Sachverständigenkommision Zwölfter Kinder- und Jugendbericht (ed.) Band 3: Kompetenzerwerb von Kindern und Jugendlichen im Schulalter. S. 95-174.

Hummrich, Merle. 2002: Bildungserfolg und Migration. Biographien junger Frauen in der Einwanderungsgesellschaft. Opladen.

Kramer, Rolf-Torsten. 2002: Schulkultur und Schülerbiographie. Rekonstruktionen zur Schulkultur II. Opladen.

Krüger, Heinz-Hermann/Grunert, Cathleen (ed.). 2002: Handbuch der Kindheits - und Jugendforschung. Opladen.

Prenzel, M. i a. 2004: PISA 2003. Der Bildungsstand der Jugendlichen in Deutschland - Ergebnisse des zweiten internationalen Vergleichs. Münster.

Toyama-Bialke, Chisaki. 2002: Elterliche Erziehungsvorstellungen in Japan und Deutschland. In: Kreitz-Sandberg, Susanne (ed.) Jugendliche in Japan und Deutschland. Opladen: 91-117. 